\title{
Excavation on the Moon: Regolith Collection for Oxygen Production and Outpost Site Preparation
}

\author{
John J. Caruso, ${ }^{*}$ Dan C. Spina, ${ }^{\dagger}$ Lawrence C. Greer, ${ }^{\ddagger}$ Wentworth T. John, ${ }^{\S}$ Clem Michele, ${ }^{* *}$ \\ Mike J. Krasowski, ${ }^{\dagger \dagger}$ and Norman F. Prokop ${ }^{+\dagger}$ \\ NASA Glenn Research Center, Cleveland, Ohio 44135
}

\begin{abstract}
The development of a robust regolith moving system for lunar and planetary processing and construction is critical to the NASA mission to the Moon and Mars. Oxygen production may require up to $\mathbf{2 0 0}$ metric tons of regolith collection per year; outpost site development may require several times this amount. This paper describes progress in the small vehicle implement development and small excavation system development. Cratos was developed as a platform for the ISRU project to evaluate the performance characteristics of a low center of gravity, small $(0.75 \mathrm{~m} \times 0.75 \mathrm{~m} \times 0.3 \mathrm{~m})$, low-power, tracked vehicle performing excavation, load, haul, and dump operations required for lunar ISRU. It was tested on loose sand in a facility capable of producing level and inclined surfaces, and demonstrated the capability to pick up, carry, and dump sand, allowing it to accomplish the delivery of material to a site. Cratos has demonstrated the capability to pick up and deliver simulant to a bury an inflatable habitat, to supply an oxygen production plant, and to build a ramp.
\end{abstract}

\section{Introduction}

$\mathrm{T}$ he Human Robotics Systems (HRS), In-Situ Resource Utilization (ISRU), and Structures and Mechanisms Exploration Technology Development Projects are working jointly to develop integrated mechanisms and mobility systems for lunar applications. The projects envision needs for capabilities to operate inside and outside a polar crater.

The development of excavation systems and mobility systems for the moon presents many challenges still to be overcome. Existing vehicles (i.e., on Mars) operate over easy terrain, collect sunlight for power, and operate in daylight. Polar vehicles and systems are likely to operate in an environment with difficult terrain, carry their own small power supply, and operate in the dark or shadow. In addition some polar vehicles should be designed to operate at the polar surface and the crater floor requiring operations over a large temperature range and very cold temperatures. They should be proficient at steep terrain, rugged terrain (for long traverses and crater floor operations), dark operations, intermittent telemetry, and low power usage. Carnegie Mellon University (CMU) and Glenn Research Center (GRC) are working to develop capabilities to achieve polar mobility proficiency. CMU has been developing a vehicle to meet many of the challenges. ${ }^{1}$ Their tracked vehicle was aimed at operations on steep slopes and in lose soil.

One method for conducting regolith delivery and construction on the lunar surface is small implements and small systems. Cratos, a small excavation system Fig. 1, was developed as a companion to the CMU work as a first step in evaluating small excavation systems for loosely consolidated lunar regolith. Delivering regolith for oxygen production and covering an inflatable structure are very focused on the lose regolith within the first $10 \mathrm{~cm}$ of the lunar surface.

The excavation system was tested in a simulated regolith. Several choices of simulant were considered. A high fidelity JSC-1 was in limited supply. A facility large enough to test a small system was not available. A facility with a low fidelity simulant had been recently constructed and was filled with sand. The sand simulant was in general

\footnotetext{
*Aerospace Engineer, Advanced Capabilities Project Office, 21000 Brookpark Road, and non-member

${ }^{\dagger}$ Engineering Technician, Jacobes, TFOME 21000 Brookpark Road, and non-member

*Electronics Engineer, Optical Instrumentation and NDE Branch, 21000 Brookpark Road, and non-member

${ }^{\S}$ Engineering Technician, Serra Lobo TFOME 21000 Brookpark Road, and non-member

${ }^{* *}$ Aerospace Engineer, Optical Instrumentation and NDE Branch, 21000 Brookpark Road, and non-member

†Electronics Engineer, Optical Instrumentation and NDE Branch, 21000 Brookpark Road, and non-member

*Electronics Engineer, Optical Instrumentation and NDE Branch, 21000 Brookpark Road, and non-member
} 


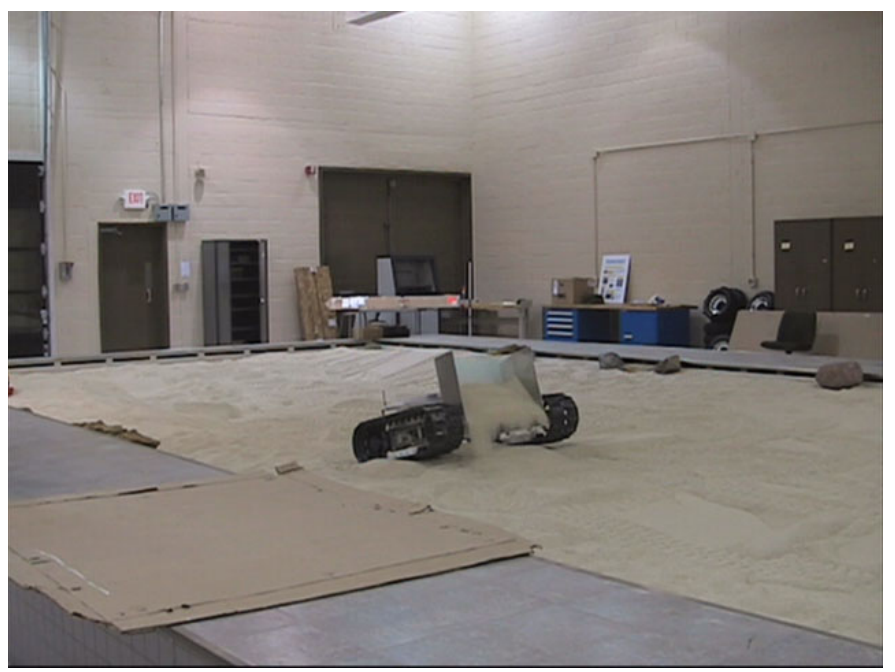

Figure 1. Cratos building a small ramp.

production and the particle size and properties were verified and acceptable for initial development testing. The lose sand (a low fidelity simulant) was a good starting point to verify a first generation small excavation system.

The vehicle has a low center of gravity, operates on less than $100 \mathrm{~W}$, and was designed to recharge secondary batteries by plugging into the lunar power grid or lander power. The vehicle could carry a small simple photovoltaic array system and recharge while in the sun. The Cratos excavation system operates from twin $12 \mathrm{~V}, 18 \mathrm{Ahr}$ Sealed Lead Acid batteries. The track motors operate at $2 \mathrm{~A}$ at $24 \mathrm{~V}$ and the bucket motor operates at $1.6 \mathrm{~A}$ at $24 \mathrm{~V}$. The system weights $80 \mathrm{~kg}$ and the bucket (75 percent full) carries a load of $23 \mathrm{~kg}$. The excavation system has a simple remote control system and requires an operator. The vehicle has been operated with a camera which displays the image on a computer for distance operations. It's current configuration requires line of site for the operator.

The system is slow moving to keep the power usage low. The bucket has not been optimized and uses a small motor to operate again to keep power low. Cratos is designed to operate $16 \mathrm{hr}$ in every $24 \mathrm{hr}$. Cratos was tested on sand, cement and asphalt.

\section{Cratos Preparation Testing for Field Demonstrations}

\section{A. Simulant Delivery to a Site/Hopper for Oxygen Production}

Oxygen production has been identified in the lunar architecture with the requirement to manufacture $2000 \mathrm{~kg}$ of oxygen per year. The architecture has several variations. One identifies $1000 \mathrm{~kg}$ of oxygen to come from regolith and the other $1000 \mathrm{~kg}$ from another source. Production of $1000 \mathrm{~kg}$ of oxygen with the lowest yields requires $415 \mathrm{~kg}$ of regolith per $24 \mathrm{hr}$ period. A small excavation system can satisfy the regolith need to produce the required amount of oxygen.

Oxygen production on the moon will require the delivery of regolith to a hopper of the oxygen production plant. The oxygen production is based on collecting lose regolith within the first $10 \mathrm{~cm}$ of the surface. The In-Situ Resource Utilization project is planning an oxygen production field demonstration that requires the delivery of a regolith simulant to a hopper. Cratos is one excavation and delivery system demonstrating the concept and feasibility of using a small mobile platform to meet oxygen production needs. Cratos was tested in a variety of conditions. The tests were conducted with sand as a regolith simulant. The tests were conducted in the indoor Simulated Lunar OPErations (SLOPE) facility. Cratos was tested on flat sand and delivered sand to a site from within a $5 \mathrm{~m}$ circle Fig. 2(a). The system was also tested on a slope of 10 degree sand and delivered sand to a site from within a $5 \mathrm{~m}$ circle Fig. 2(b).

The excavation system picks up one bucket load and delivers it. One bucket load is about 75 percent full and weighs $23 \mathrm{~kg}$. The system can deliver $150 \mathrm{~kg}$ to a site within $10 \mathrm{~min}$ when the collection area is within a $5 \mathrm{~m}$ circle. The 10 degree slope had slight slowing effect but still completed the task in $10 \mathrm{~min}$. The system was operated by several remote control drivers. 


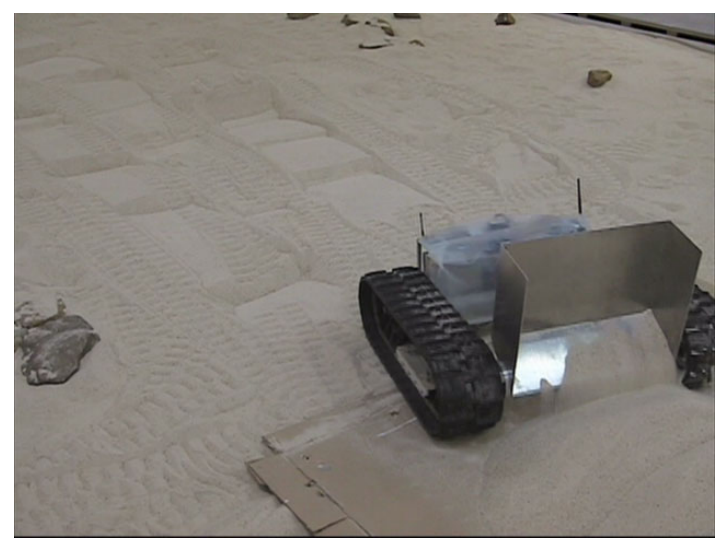

Figure 2(a) Flat excavation and delivery.

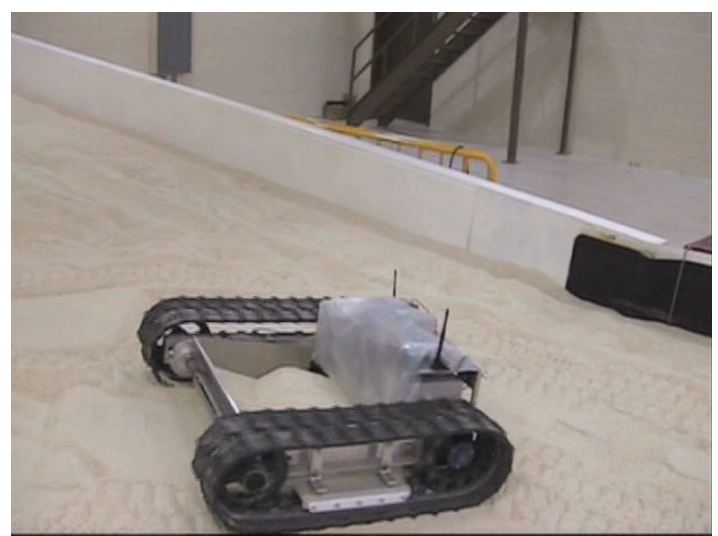

Figure 2(b) Side slope excavation and delivery.

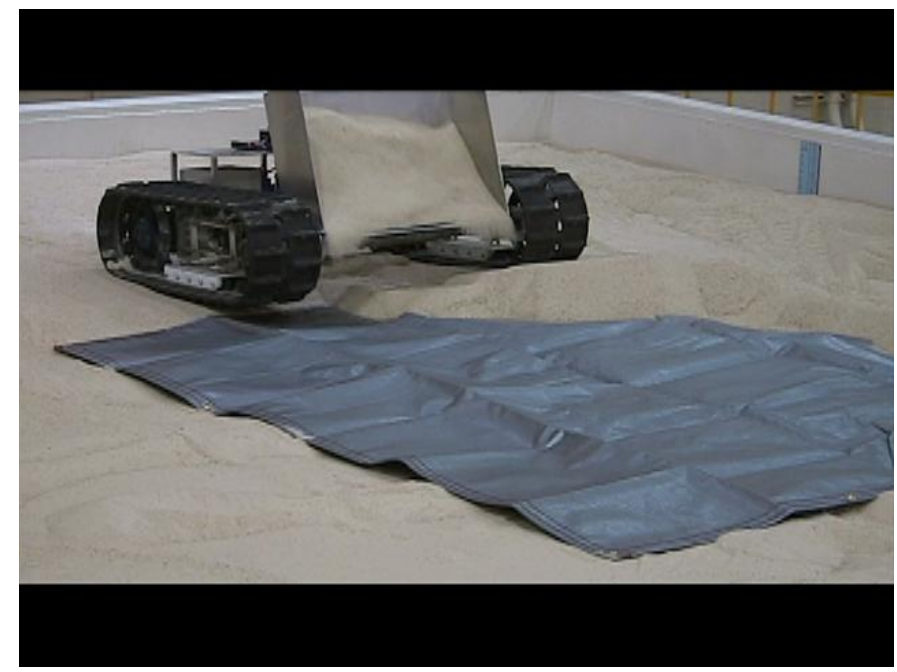

Figure 3 Cratos dumping a load of sand on a tarp.

\section{B. Regolith Delivery for Radiation Protection}

Radiation shielding is a critical consideration for the moon and has been proposed as a good material for shielding by several organizations. The Structures and Mechanisms team is one organization considering shielding habitats with regolith. The quantity of regolith required is larger than that needed for oxygen production but still the lose surface material. One option is an inflatable that requires the vehicle to cover the un-inflated system with regolith.

The Structures and Mechanisms project is preparing for a lunar habitat regolith lifter field demonstration. The excavation system will deliver regolith to cover the inflatable to the required depth and then the system will inflate. One purpose of the test is to load the inflatable with simulant without damaging the system. The field demonstration will require the simulant delivery system to dump simulant on the inflatable without driving directly on the material. Once a base of simulant is on the inflatable the delivery system can drive on the simulant to totally cover the habitat.

A plastic tarp was use as a surrogate for the inflatable. The tarp is very sensitive to reactions if the vehicle hits it or if driving on the simulant and the tarp cause a problem. The test was conducted in the SLOPE facility with sand. It is expected that another simulant will be used for the test and Cratos will have to do some testing with it. Cratos did a very good job in dumping on to the edge of the tarp Fig. 3. Once the edge was covered Cratos drove on the simulant above the tarp. The tarp did not appear to be effected by this operation. Cratos continued till the tarp was covered. 

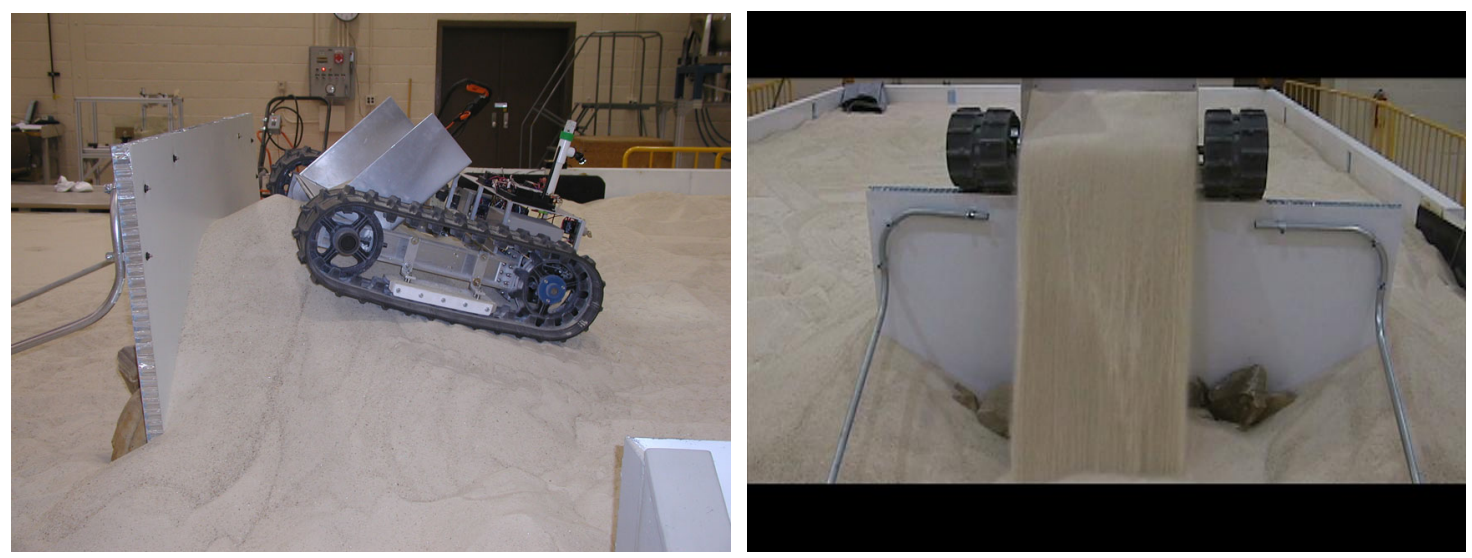

Figure 4 Ramp partially constructed (left) and complete (right).

\section{Regolith for Ramp Building and Construction}

Many operations on the lunar surface will require a ramp for access. The oxygen production field demonstration being conducted by the ISRU project will require a ramp. In an attempt to save mass and volume, ramps built from regolith are being considered.

Cratos built a small ramp as part of the initial testing of the excavation system. The ramp was a small free standing ramp of about $0.2 \mathrm{~m}$ Cratos was able to drive on the ramp as it was being constructed and when completed.

Building a ramp for oxygen production may require a higher vertical step, so a larger ramp test was conducted. In this case a $1.0 \mathrm{~m}$ back board will be used to build a $1 \mathrm{~m}$ ramp. The sand simulant is collected and delivered to the ramp Fig. 4. At the completion, Cratos delivers a load over the ramp as a demonstration of delivery to a hopper.

The test demonstrates the potential to build a ramp from regolith on the moon. Building the ramp $1 \mathrm{~m}$ high took around $8 \mathrm{hr}$ and the vehicle was able to ascend and dump sand to the other side.

\section{Summary}

Small excavation, delivery, and construction mechanisms and systems for lunar applications are capable of doing many tasks required for a lunar outpost. Lab tests have demonstrated the initial capabilities of small low power systems. Cratos is capable of building ramps and delivering regolith for many applications.

\section{References}

${ }^{1}$ Josh Johnston, Jason Ziglar, William Whittaker, et al., "Icebreaker: Lander/Rover Scenario and Technologies Toward Lunar Crater Exploration," Final Report to NASA Glenn Research Center for GRC-X-001-0799, Carnegie Mellon University, Pittsburgh, PA, May 31, 2006. 